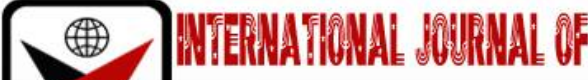

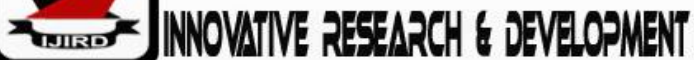

ISSN 2278-0211 (Online)

\section{Repositioning Fine and Applied Arts for Employment Opportunity and Wealth Creation}

\author{
Ibrahim Mamman \\ Lecturer, Department of Industrial Design, Ahmadu Bello University, Zaria, Nigeria \\ Samson Musa Andenumra \\ Lecturer, Department of Fine and Applied Arts, \\ College of Education, Zing Taraba State, Nigeria \\ Danjuma Andembutop Kwesaba \\ Lecturer, Department of Hospitality and Tourism Management, \\ Fedral University Wukari, Taraba State, Nigeria
}

\begin{abstract}
:
With the rate of unemployment in Nigeria towering high above all expectations, if nothing is done urgently to salvage the situation by government and spirited individuals and organizations, the youth may have nothing left than to engage in all forms of societal ills such as kidnapping, insurgency and terrorism. Also, lack of knowledge for business, managerial skills and even fear of the unknown, have crippled the youth from venturing into private businesses that promote selfreliance. In the face of this global economic crisis in the country, Nigerian educational system needs to turn out graduates who will be "job creators' and not "job seekers'. This paper therefore focuses on ways of tackling unemployment and wealth creation through Fine and Applied Arts education, with the hope of stamping out joblessness and poverty in the country. It is in the light of this unemployment problem and over-dependence on government that this paper attempts to examine the roles and contribution of Fine and Applied Arts education to boosting employment and wealth generation in the country. The paper also tries to outline some of the problems that militate against education through Fine and Applied Arts. Finally, the paper recommends among other things ways of tackling these problems with the view to promoting the benefits of Fine and Applied Arts to the society. It is our belief that an opinion paper such as this which attempts to support government's emphasis on entrepreneurial education for our youth today cannot come at any better time.
\end{abstract}

Keywords: Unemployment, economic crisis, wealth creation, functional education, fine and applied art education, and entrepreneurial education

\section{Introduction}

Fine and Applied Arts education as a discipline taught in schools in Nigeria is one of the Humanities which develop creative skills and aesthetic sensibilities within the framework of the discipline of education. It is a special kind of education which utilizes art forms as the media for stimulus-responses in learning situations and the education-package itself is capable of being perceived and appreciated as a master piece of art (Uzoagba,1991 and Okoli, 2007 as cited in Andenumra, 2011). Fine and Applied Arts education as one of the functional education emphasizes on wealth generation, economic sustainability and above all, self-reliance. It prepares and builds persons to be responsible and enterprising individuals capable of deep entrepreneurial thinking which contributes towards economic and sustainable development. It focuses on practical experience and expertise that is needed for commerce and business opportunities.

Functional education, according to Unachukwu (2009), is the process through which individuals are made to be participating members of their society. It enables them to become capable of living in the society and to contribute towards its economic development. This shows that functional educational system takes cognizance of the dynamics of the labour market, equips its graduates with occupational skills and competence needed to be self-reliant.

Fine and Applied Arts as an entrepreneurial discipline is associated with a number of activities which include the ability to create and build something from nothing; the ability to possess a vision matched with a focus and determination of building an enterprise; the ability to see an opportunity where others fail to see it; the ability to aggregate, marshal and control resources judiciously; the willingness to undertake personal and financial risks; and the ability to engage in activities despite all odds and facts surrounding these odds and possibly turning them into your own favour (Dangote, 2002 as cited in Odjegba,2005). From the foregoing, one can conclude that Fine and Applied Arts education is an instrument per excellence that a nation can rely upon for self-reliance. The National Policy on Education has given recognition to Fine and Applied Arts because of its role as an instrument for self-reliant economy. As Mamza (2007) puts it: "it is one of the disciplines in our educational programme that avails trainees the opportunity to acquiring skills, 
abilities and competence both mental and physical as equipment for the individual to live and contribute to the development of the society. Aboli and Amokaha (2012) added that Fine and Applied Arts as an entrepreneurial discipline lies in the creation of jobs, stimulation of innovation and provision of opportunities for various people in the society.

\section{The Concept of Fine and Applied Arts, Employment and Wealth Creation}

It is imperative at this juncture to proffer operative definitions and to explain the concepts of Fine and Applied Arts, employment and wealth creation as they relate to the theme of this conference.

\subsection{Fine and Applied Arts}

For the purpose of clarification, the concept of Fine and Applied Arts can best be understood when each is looked at separately. The word 'Fine' according to Uzoagba (2000) has to do with appreciation of beauty and is used to describe that branch of art which has no other function than the appeal to human sense of beauty and higher emotion. Painting, sculpture, drawing and art appreciation belong to this branch of visual art. "Applied art' on the other hand addresses the making of objects to serve a particular purpose or to perform certain functions which they are intended to serve. Often, such objects are beautiful as well. Such areas known as "applied arts' include graphics, textile design, ceramics, industrial design, photography, cabinet making, glass technology and interior decoration

Art, according to Uzoagba (2000), has been defined by some scholars as a controlled spontaneous activity having to do with theory and practical of taste in the expression of beauty, significance of form, colour, sound, speech and movement. Others describe it as communication of emotions or ideas, self-expression, sophisticated play, seeing the world afresh, sublimation and intrinsic values. Still others look at art as the skill applied to the art of imagination and design which has to do with feelings as opposed to knowing and doing. It is also said to be the power of doing something not taught by nature or instinct (Banjoko, 2000). All the foregoing definitions are the several attempts to explain what art is all about. If one should put all these attempts into consideration, one would arrive at the conclusion that the concept art actually has to do with human effort to express oneself via a medium skillfully, and with the attempt to please or communicate an idea. However, it is not every expression via a medium that is artistic, except when it creates pleasing forms that satisfy our sensibility and craving for beauty or aesthetic values.

\subsection{Employment}

Employment, simply put, often refers to the process of being engaged in some gainful job or activity which at the end generates a pay on a regular basis. For most people, the sole aim of going to school is to be educated and at the end gain employment. For most Nigerian youth, the target is government employment; what is often referred to as white-collar job. But in a situation whereby the school product ends up roaming the streets without employment is not only frustrating, but can create emotional stress which could lead to mental or physical breakdown. No wonder, many of them end up being drug addicts and eventually terminating in some mental homes or in the hands of restive groups such as Boko Haram in North-east Nigeria or Niger Delta militants.

Before we look at why many go unemployed, let's consider the concept of unemployment as defined by various writers. According to Victor (2009), unemployment refers to situations in which people that are qualified by age to work but cannot find employment. It is a situation in which people that are capable of working do not get engaged in employment which can either be of permanent, contractual or part-time nature. Mohammed (2011) as cited in Balogun (2012), quoted the Chief Executive Officer of Dangote Groups of Companies, Alhaji Aliko Dangote, as saying that "in Nigeria the issue of youth unemployment in the country where more than half the population is youth is a matter of national importance and national urgency'. Nigeria cannot grow and develop if more than half of its population is not working; either because there are no jobs or because they lack the skills. Most worrisome in this emerging paradox is the fact that the highest rate of unemployment is in our rapidly expanding youth population. In other words, our youth population is unemployed or under-employed at the peak of their productivity age.

\subsection{Wealth Creation}

Wealth creation addresses the making of money or capital from the proceeds of employment. World Bank (2008) states that, as traditional job-for-life career paths become scarce, youth entrepreneurship can provide an additional way of integrating youths into today's changing labour market and improve their economic independence. For some young people in our state, Taraba, and in Nigeria at large, self-employment provides paths for growth and the development of human capital.

Fine and Applied Arts therefore, as one of the sources of employment and wealth creation, can unleash the economic potentials of young people. It can also be a source of new job opportunities and growth, improving their economic independence if government can reconsider its educational priorities and repositioning certain entrepreneurial disciplines.

\section{The Role and Contribution of Fine and Applied Arts Education for Employment and Wealth}

Fine and Applied Arts education has been recognized as an essential tool for youth employment in Nigeria by both Nigerian educationists and government alike. For this aspiration to be realistic there is a need to diversify the discipline into the various fields of specialization, where special attention can be accorded to each. The various branches of the arts include the following: 


\begin{tabular}{|c|c|c|}
\hline Fine Arts & Applied Arts & Crafts \\
\hline Painting & Textile & Basketry \\
\hline Sculpture & Graphics & Calabash Carving/Decoration \\
\hline Drawing & Ceramics & Mat Making \\
\hline Art Appreciation & Glass Technology & Carving \\
\hline & Industrial Arts & Leatherwork \\
\hline & Commercial Design & Blacksmithing \\
\hline & Metal and Jewery \\
\hline & Interior Decoration & \\
\hline
\end{tabular}

Table 1

\subsection{Fine Arts}

As earlier on mentioned, these are the areas of art which appeal only to man's sense of beauty or aesthetics and the higher emotions and havingno other utility functions. They include: Painting, Sculpture, Drawing and Art Appreciation. Each is a distinct area of specialization; which students can choose to major up in any and become professionals. Each shall be discussed as follows:

\subsubsection{Painting}

Painting is the use of colours, illustrations and drawings based on creativity and originality of thinking. It enables us to create works of art using various techniques such as: Collage, Mosaic, Photomontage, landscape, seascape, portraiture, mix-media, and so on. It is worthy to note that even though painting as a human activity has become decorative and so called "Fine Art' today; that was not the original function when it was first created on the walls of our cave-dwelling ancestors, the Stone Age people. Painting then, was utilitarian, it was real, and it was the magic that the primitive man needed to survive in his harsh environment (Gombrich, 1995). It is the belief of this paper that right from the early stages of man's civilization and development, painting as an aspect of art was already an honourable occupation; those who were involved in creating paintings were highly respected. In fact, they were the chief priests of their society and wielded great power. If that honour, respect and power are converted to monetary terms in our time, what an affluence and influence a painter can wield?

\subsubsection{Sculpture}

Sculpture is the field of specialization where the individual is taught various skills in modeling, smithing, metal work, relief, carving, just to mention but a few. Like painting, the art of sculpture or simple clay modeling and miniature stone carvings were as old as man himself. The desire to sculpt sprung out of the necessity to live: to be fruitful and to protect that which one has. That human craving metamorphosed into a religious belief-system where faith was both a formidable weapon against the forces of the unknown and also a powerful instrument of favour from the creator. Small pieces of sculpture were used by the Stone Age men as goddesses of fertility and as guardian angels; and one can imagine the 'vogue' as every home desiring fruitfulness and protection must 'commission' these magico-religious sculptures. This paper has taken the pains to delve into all these to prove how important art was in the time past and how those who made them wielded power in their society. The realization of the importance of art can also be made possible in our time if the arts are accorded their rightful place in our society.

\subsubsection{Drawing}

This involves the production of various types of drawing either in pencil, pen and ink, charcoal, pastel, crayon, engraving, and so on. The one who is good in drawing can attract a lot of commission. In the Western world, a good draftsman is job-winner, as he is needed everywhere from the police department to filmstrip or comic strip houses. In the United States particularly, the draftsman is a very busy business man, designing all kinds of industrial items to cartoons in comic strip houses. He is not a useless man as Nigerians would like to call him.

\subsubsection{Art Appreciation}

This trains in recipients the ability to appreciate beauty in art and in nature by observing and comparing various works of art, thereby considering their various aspects in respect to their production such as the form, materials used, methods of production, their value, their significance, originality, self-expression, draftsmanship and the skills of display and arrangement. An expert in Art Appreciation is a consultant and could render service to all classes of the society that values art; from theatre homes to owners of parks and other recreational centres.

\subsection{Applied Arts}

As opposed to the Fine Arts, this aspect of art involves the production of objects whose primary purpose is to function as an item of utility for various human needs. The beauty or the art aspect is applied and secondary. Applied Arts cover the followings areas: Graphics, Textile, Ceramics, Glass Technology, Industrial Arts, Metal and Jewelry, Commercial Design, Interior Decoration, and so on. They will be discussed as follows: 


\subsubsection{Graphics}

It is an aspect of art that deals with design concepts; and analysis being the immediate needs of the industries and institutions that commission their production. They include typography, photography, letterings, applied design, illustrations, developing, advertising, package design and book design. This is the only aspect of Applied Arts that Nigerians respect because graphic designs take place in every street corners of our society. But those roadside artisans, who design billboards, signboards, etc., are only a microcosm of graphic artists, yet they are making it. What would be the case if real graphic artists are commissioned do such works themselves?

\subsubsection{Textile}

This addresses the design, application, production and assessment of fabrics. It has the following methods of production: dyeing, weaving, printing, knitting, sewing, fashion design, furnishing, and so on. Textile designers in the country would have been doing better than even graphic artists in business because everybody has need of clothing, but the case is a reverse. This is so because many Nigerians have the wrong notions that those clothes are machine done and so, see no human connection. But even the machine-produced textile materials have the motifs or designs created first by artists. Secondly many textile designers are poor and do not do as well as their graphics counterparts because most textile industries which bloomed 30 years ago have become shadows of themselves today because of preference for foreignmanufactured fabrics.

\subsubsection{Ceramics}

This covers the production of wares made of clay and related materials for utilitarian purposes. Among ceramic products are cups, pots, jugs, plates, sanitary wares, bricks, tiles, electric insulators, etc.

\subsubsection{Interior Decoration}

This refers to the processes of decorating the interior of houses, rooms, cabins, etc. These decorations can be in the following methods: painting, mosaic, carpentry, wall hangings, tapestry, blinds, etc.

\subsubsection{Commercial Design}

This involves the art of adding graphic expressions to products and services, labeling or advertising, packaging, organizing, marketing or presenting ideas that will attract customers or consumers. The aims of commercial designs are to impress consumers so as to sell the mass-produced goods from factories to as many as possible.

\subsubsection{Industrial Arts}

These involve the designing of a wide range of products which include vehicles, machines, implements and many more things around us. It is the integration of art, engineering and merchandising.

\subsubsection{Photography}

Is an art of creating an image with light by focusing and shooting such image through the lens of a camera; and turning such image into pictures after undergoing some processes.

\subsection{The Crafts}

Crafts cannot be included in the classification of the branches of art because of their localized nature. Most crafts are produced by local communities all over the world and are yet to be internationally standardized as the arts (Banjoko, 2000). Crafts address the domestic and utility needs of particular communities, and because they primarily attend to functions ascribed to them, they require less skill and do not necessarily attain the aesthetic standard of art works. For example, a hoe is made primarily to be used to plough or till the ground and does not have to be beautiful, even though some of them are very beautiful. The more time and attention an artisan put to making a craft more beautiful, the more it moves away from craft to an art work. That is the reasons why some scholars today find it difficult to differentiate between an applied art and a craft. Crafts include basketry, calabash work, carving, leatherwork, blacksmithing, pottery, etc. All these areas also offer ample employment and wealth creation opportunities for interested Nigerian youth, and some are discussed as follows:

\subsubsection{Weaving}

Weaving is simply the interlacing of flexible materials to form patterns and a product or a form. There are various types of weaving, which include: basket weaving, mat weaving, fabric weaving, rug weaving, straw weaving, cane weaving, etc. In any type of weaving, the principle is the same, although the technique, style and patterning may slightly differ. The art or craft of weaving has been as old as man, for evidence of some archaeological discoveries point to that fact. As varied as its techniques and products are, so is the vocational opportunities it offers to trainees.

\subsubsection{Fabric Design}

Fabric designs include all the decorative techniques that are applied unto a fabric often referred to as resist methods or techniques. Basically, there are two techniques, namely, tie and dye and batik. Tie and dye technique which refers to the methods of tying portions of the fabric and dyeing in order to achieve certain patterns has the following methods of designs: concentric squares, circle methods, clump tying, pleating method, marbling, knotting, and stitching. 
Batik which is a wax-resist method of dyeing fabrics is popular among the Yorubas of Western Nigeria. It has only one method which is referred to "Tjanting' and involves lots of procedures.

\subsubsection{Calabash Carving and Decoration}

Calabash is simply a gourd. Gourds are fruits of a crawling or climbing plant grown usually in rubbish heaps, even though organized cultivation can be done. The fruits when matured are plucked, cut and placed face-down to ferment, washed and dried before decorating. The methods of decoration include scorching or burning, incising or engraving, painting and the addition of extraneous materials like cowries, beads and coins especially for some spiritual or ceremonial purposes. Each method of decoration differs according to the community and function in which the calabash is to serve. Some are left undecorated. Calabashes are used as containers, musical instruments, fishing floats, and a host of other traditional purposes. Calabash decoration is a thriving business both in the south-west and north-east Nigeria, particularly in places like Oyo and Gashua in the south-west and north-east Nigeria respectively.

\subsubsection{Blacksmithing}

Blacksmithing is the art of melting metals to form a variety of shapes for various implements. Its products cover a wide range of farm implements, household utensils, ornaments, musical instruments, ceremonial and ritual objects, hunting implements such as Dane guns, arrows, spears, etc. In most cases the art of blacksmithing consists of guild groups that control their operation; and it is often heredity, a craft between father and son.

\subsubsection{Leatherwork}

This is the production of decorative and functional objects mainly from hides and skin. Several techniques are used in decorating leather, which include painting, burning with knives, brushing, dyeing, embroidery, incasing and addition of extraneous materials. The tradition and trade in leather products has been an old-time business in Northern Nigeria where the raw materials are in abundance.

\subsubsection{Carving}

Carving, according to Banjoko (2000), is a subtractive process by which some unwanted areas of a solid piece of material such as wood, stone, metal or even bone are cut or chipped away to create a new form. It is the direct opposite of modeling technique. Carving in Nigeria is a popular art especially in Southern Nigeria where wood in variety of species abound. Among the variety of objects carved are house posts, door panels, household items such as stools, mortar and pestles, variety of sculptures, etc.

From the foregoing discussion on the various fields of Fine and Applied Arts education, the discipline, as a school subject, offers various gainful job and wealth creation opportunities for the unemployed Nigerian youths who choose to interact in any of the various fields of specialization. After he or she may have gained enough entrepreneurial training experience in the field or fields of his or her choice, he or she can confidently set up his or her own enterprise and yet provide employment opportunities for other youths.

\section{Problems That May Likely Confront Fine and Applied Arts Sector in Job Creation and Wealth Acquisition}

Timmons (2008) opined that Nigeria as a nation has seen many economic packages with the objectives to boost job and wealth creation opportunities within the country such as the Green Revolution, Austerity Measures, Structural Adjustment Programme, Privatization, Monetization, Consolidation Programmes, just to mention but a few. However, many factors have accounted for the failure of these laudable programmes to restore any remarkable confidence in the nation's economic system. It is noteworthy to say here that none of the factors for the failure of these programmes is more devastating than the lack of entrepreneurial education. Entrepreneurial education, which accords learners with the real experience which enables them to understand how entrepreneurs think and behave; how they take risks; how they organize their work; how they find customers; how they handle diverse activities; and how they make their final decisions to succeed, when absent, there is bound to be frustration and failure.

Another factor for failure which has limited or discouraged youths from venturing into business is the poor conception accorded to Fine and Applied Arts education in our society. Most Nigerian youth prefer white-collar jobs to being selfemployed, particularly in the Fine and Applied Arts, because they consider it to be a dirty or crazy man job. But more often than not, the white-collar jobs they so much desire are a far cry, and so frustration and despair set in.

Another factor that militates against employment and wealth creation opportunities in the Fine and Applied Arts is that lack of public awareness of what the discipline itself mean and the value it holds for the society. To many, it is merely painting and drawing and so, is useless. They often find it hard to believe that they are living with and daily using products of Fine and Applied Arts; their choice of consumable items including food is determined by art products. In other words, the houses they live in, the clothes they wear and the food they eat have aspects of art, especially the aesthetic aspect, incorporated into them, as can be seen in colours and labels that determine their choice of one thing or the other. Also, lack of adequate qualified personnel or professionals in the field of Fine and Applied Arts to train the youth in the various fields of specialization and with the entrepreneurial skills that government now emphasizes. This entrepreneurial aspect of education that Fine and Applied Arts can offer is very crucial to the theme of this conference and it is the crux of why we find so many graduates and job seekers roaming the streets today without any meaningful thing to do.

Yet another factor is the lack of vocational and technical facilities and infrastructure to encourage the training in the various fields of specialization in the Fine and Applied Arts. Most educational institutions operate the programmes in Fine and Applied Arts without any meaningful equipment and materials on ground. In fact, some learners graduate in 
these programmes without handling some of the most basic equipment and tools. Concerning infrastructure, Nwachukwu (1998), as cited in Enyekit \& Abara (2009) noted that many development programmes are not properly planned and there are no sequences to the courses offered from year to year, and one of the underlying factors is the lack of planned infrastructure to achieve goals.

Another factor militating against the proper training in the Fine and Applied Arts is the high cost of some tools and materials. This is really a thing of concern, because most of the ready-made industrial materials are either very expensive or very scarce to find. Sometimes one has to go to very far distance like Lagos, Benin City, Port Harcourt or Kano, etc., to get them. Most often the poor students cannot afford to buy them, and so resort to improvising them, but the problem is also with the skill to improvise thereby leading to poor quality of work. Most teachers of Fine and Applied Arts and other vocational and technical education today lack the requisite vocational skills expected of professionals that will enhance self-reliance and economic development of our society (Sulyman, 2012).

\section{The Way Forward}

We would want to posit at this juncture that Fine and Applied Arts education is gradually becoming a more relevant tool for our socio-economic development and a work force realization of our nation, Nigeria, despite all the odds militating against it, as aforementioned. Thanks to government realization and current emphasis on entrepreneur education in our institutions of higher learning. This is what Fine and Applied Arts education has been preaching silently for over a century now through the activities of its educationists and professionals; from Pa Aina Onabolu and Akinola Lasekan to Professor Ben Enwonwu, Professor Bruce Onabrakpeya, Professor Jimoh Akolo, and a host of others; that a product of Fine and Applied Arts education is already self-employed after leaving school because of the nature of his training and profession. It may be rightly deduced that Fine and Applied Arts education can truly be used as an instrument per-excellence for job and wealth creation, if proper planning, adequate funding, relevant materials and facilities and above all personnel who are not only competent but committed and determined to succeed, are put in place.

\section{Recommendations}

Based on the foregoing argument on the place of Fine and Applied Arts education on the map of entrepreneurial education in Nigeria; and the focus of contemporary education to turn out job creators rather than job seekers, this paper wishes to recommend the following:

- That government and its education agencies should without delay review the content of Vocational and Technical Education Curriculum with the view of streamlining it along the aims, goals and objectives of entrepreneurial education.

- That stakeholders of Fine and Applied Arts education should ensure that they are producing professionals who not only understand the peculiarity of their profession but possess what it takes to solve the problem of unemployment and poverty in this country.

- Teachers of Fine and Applied Arts education should sensitize learners with the cultural, social and economic values and needs of their society, so that what the students turn out will reflect these aspirations; thereby cutting off unnecessary outside influences that conflict with these values.

- That through persistent public propaganda and awareness about the importance of our culture and cultural identity and the place of art in all these; and proper sensitization at the elementary and secondary levels of education, our society will change its negative attitude towards education through Fine and Applied Arts.

- Finally, to redress the situation of our present educational system and gear it towards economic growth and wealth generation, it is pertinent that a multidimensional and integrative approach should be enforced in our teaching methods by the collaborative efforts of both government and non-governmental agencies through their support in the supply of appropriate materials and organizing sensitization workshops and conferences at all levels.

\section{References}

i. Abefe, B. (2012). Advances in arts, social sciences and education Research. Retrieved (Month, date, year) from http://www.ejonal.bedinst.com

ii. Amokaha, G.S \&Aboli, D.E. (2012). Visual arts education and Unemployment question in Nigeria. SOVATE Journal, Zing vol. no.1, 2012

iii. Andenumra, S.M. (2011). Improving aesthetic quality of the environment using art education in Jalingo, Nigeria (unpublished Masters Dissertation submitted to the Department of Fine and Applied Arts, University of Nigeria, Nsukka)

iv. Enyekit, E. O. \& Obara, J.K. (2009). Projecting Nigeria into the new end of the first quarter 25 years of the $21^{\text {st }}$ century in vocational and technical education. African Journal of Education and research development 1 (1), 2-8

v. Enyekit, E.O., Amaehule, S. \&Teenah, L.E. (2011). Achieving human capital development in Nigeria through vocational education for nation building. International Association for Teaching and Learning (IATEL)

vi. Jeffery, T. (2008). Criteria for youth / Ai/ Entrepreneurship \%20 Education \%20 Concepts.htm

vii. Lanre, O.S. (2012). Qualitative skill - assured teacher education: a necessity for achieving vision 2020. SOVATE Journal, Zing vol.1 no.1 2012

viii. Mamza, A. (2007). Contemporary issues in fine and applied arts education in Nigeria. Multidisciplinary Journal of Research Development Vol.8 No.4 2007 
ix. Unachukwu, G.O. (2009). Issues and changes in the development of entrepreneurship education in Nigeria. ISSN 1994 - 9057 (Print) ISSN 2070 - 0083 (online)

x. Uzoagba, I.N. (2000). Understanding art in general education. Third Edition Rex Chart \& Patric Ltd. Nimo

xi. Victor, E.D. (2009). Addressing youth unemployment and poverty in Nigeria: a call for action. No. 12 Historic Journal of Sustainable Development in Africa Vol.11 No.3 2009

xii. Banjoko, I. (2000) Visual Arts. Made Easy Textbook for Schools and Colleges Movic Publishing Company limited, plot 146, Oyadiran Estate, Sabo, Yaba, Lagos, Nigeria.

xiii. Gombrich, E. H. (1995). The Story of Art - 16th Edition Barns \& Noble Booksellers, Inc, 122 Fifth Avenue, New York, NY 10011http://www.barnesandnoble.com/w/the-story-of-art-16th-edition-eh-gombrich/1107143873 